\title{
Maltase Inhibitory Activity of Aqueous Extracts of Zingiber officinale Rosc. and Trigonella foenum-graecum Linn.
}

\author{
Janhavi Jatin Damani*, Radiya Pacha-Gupta, Nandita Mangalore
}

\section{Janhavi Jatin Damani, Radiya Pacha-Gupta, Nandita Mangalore}

Department of Life Science and Biochemistry, St. Xavier's College, Mumbai - 400001, Maharashtra, INDIA.

\section{Correspondence}

Janhavi J Damani

Department of Life Science and Biochemistry, St. Xavier's College, 5, Mahapalika Marg, Mumbai - 400001, Maharashtra, INDIA

Phone no: +91-9167262804, 02222620661

Fax: 02222659484

E-mail: janhavi.damani@gmail.com

History

- Submission Date: 23-05-2017;

- Review completed: 21-07-2017;

- Accepted Date: 19-12-2017

DOI : 10.5530/pj.2018.2.39

Article Available online

http://www.phcogj.com/v10/i2

Copyright

(C) 2018 Phcog.Net. This is an openaccess article distributed under the terms of the Creative Commons Attribution 4.0 International license.

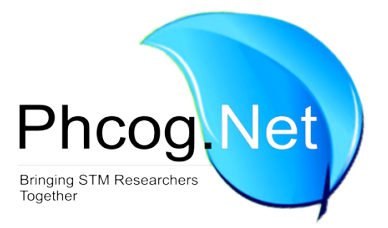

\begin{abstract}
Context: An important approach to diabetes treatment involves the regulation of postprandial hyperglycemia by delaying the release of glucose into the bloodstream using inhibitors for carbohydrate digesting enzymes such as maltase. Current synthetic antidiabetic drugs are associated with side effects that have restricted their usage. Antidiabetic plants such as Zingiber officinale and Trigonella foenum-graecum, commonly used as medicinal herbs in India, provide an attractive alternative as a source of maltase inhibitors. Aim: This study aimed to determine maltase inhibitory activity in antidiabetic plants in comparison with that of a synthetic drug, Acarbose, used as a positive control. Study Design: In vitro Enzyme Inhibition Assay. Materials and Methods: Aqueous plant extracts were prepared using rhizome of $Z$. officinale and leaves of $T$. foenum-graecum. Varying concentrations of the aqueous plant extract were tested for maltase inhibitory activity using crude yeast maltase enzyme. Statistical Analysis: Unpaired, two tailed t-test was used to detect the significant difference between the mean maltase enzyme activity of the control and that of the test. Results: The aqueous extract of $T$. foenum-graecum exhibited a higher potent maltase inhibitory activity with $I C_{50}$ value of $1.05 \%$ as compared to that of the aqueous extract of $Z$. officinale with $I C_{50}$ value of $2.13 \%$. Acarbose showed the highest potency of maltase inhibition with an $I C_{50}$ value of $0.014 \%$. Conclusion: $Z$. officinale and T. foenum-graecum have significant maltase inhibitory activity $(p<0.05)$. Thus, a contributing factor to the antidiabetic property of the two plants may be attributed to their maltase inhibitory activity.
\end{abstract}

Key words: Acarbose, Antidiabetic Plants, Maltase Inhibitory Activity, Trigonella foenum-graecum, Zingiber officinale.

\section{INTRODUCTION}

Diabetes mellitus is a multifactorial metabolic disorder affecting over 400 million people worldwide and is estimated to affect about 100 million people in India by $2030 .{ }^{1}$ Type 2 diabetes is prevalent in over $90 \%$ of the patients, whereas the remaining has type 1 diabetes. The prevalence of diabetes is most likely to double by 2030 with an increase of up to $69 \%$ in developing nations and $20 \%$ in developed nations. ${ }^{2}$ There are several conventional treatment strategies for the management of diabetes: insulin injection, stimulating insulin release using sulphonylureas, ${ }^{3}$ reducing hepatic gluconeogenesis, ${ }^{4}$ upregulating glucose transporters in target tissues using metformin, ${ }^{5}$ and reducing insulin resistance using thiazolidinediones. ${ }^{6}$ However, one of the most important antidiabetic therapeutic approaches is the use of alpha-glucosidase inhibitors, ${ }^{7,8}$ a class of antidiabetic drugs which inhibit alpha-glucosidases (EC 3.1.2.20, maltase). They are membrane-bound carbohydrate digesting enzymes located on the brush border epithelium of the intestine. Postprandial hyperglycemia is the clinical hallmark of diabetes mellitus; thus, regulating blood glucose levels is a primary goal in antidiabetic treatment in order to prevent chronic

diabetic complications. ${ }^{9}$ Postprandial hyperglycaemia is related to the digestion rate of dietary starch, which provides a direct source of glucose. Maltase inhibitors target the reduction in the rate of dietary carbohydrate digestion by inhibiting the hydrolysis of oligosaccharides to glucose and, thereby, delaying the release of glucose into the bloodstream. This reduces postprandial hyperglycemia in type 2 diabetic patients. ${ }^{10}$ Currently used maltase inhibitors such as acarbose, miglitol, and voglibose are associated with negative gastrointestinal symptoms such as flatulence and diarrhea, thereby restricting their usage. ${ }^{11-17}$ Plants are a natural reservoir of phytochemicals that act as antidiabetic agents and seldom show deleterious effects, and they may be a source of maltase inhibitors. This study aimed to detect maltase inhibitory activity in antidiabetic plants using an in vitro enzyme inhibition assay. There have been many reviews on plants and their antidiabetic properties. ${ }^{18-20}$ and in this study, out of the repertoire of antidiabetic plants found in nature, Zingiber officinale (ginger) and Trigonella foenum-graecum (fenugreek) were screened for maltase inhibitory activity. 
Maltase was extracted from Saccharomyces cerevisiae as it is an easily available, eukaryotic source of the enzyme. Upon aligning the amino acid sequences of maltase from two different sources using the BLAST tool: Homo sapiens (Human Intestinal Maltase), and S. cerevisiae (Baker's Yeast Maltase), there was $4.819 \%$ identity in the sequence. A significant effect of the antidiabetic plant extract on yeast maltase should also have a similar effect on human intestinal maltase. The aqueous extracts of these plants were tested statistically for significant difference in the maltase enzyme activity using an unpaired, two tailed $t$-test. The preliminary findings reveal that the antidiabetic property of the selected plants could be attributed to their maltase inhibitory activity.

\section{MATERIALS AND METHODS}

\section{Materials}

The plant specimens, rhizome of $Z$. officinale and the leaves of T. foenumgraecum, were purchased from local vegetable vendors at Crawford Market, Mumbai, India. The authentication of the plant specimens was conducted at the Blatter Herbarium, St. Xavier's College, and Mumbai, India. The plant material was deposited in the herbarium for future reference. Maltose Monohydrate, Peptone, and Yeast Extract were purchased from HiMedia Laboratories Pvt. Ltd., Mumbai-400086, India. Glucose Kit (ERBA Diagnostics Mannheim, Germany) was purchased from Transasia Bio-medicals Ltd., Solan-172205, India. All other chemicals and reagents were of analytical grade and obtained from LOBA Chemie Pvt. Ltd, India unless stated otherwise. Acarbose tablets (25 mg) were purchased from Bayer (India) Ltd.

\section{Preparation of Plant Extract}

Both plant specimens were washed thoroughly with distilled water to remove surface debris and air dried completely. A $10 \%(w / v)$ aqueous extract of $Z$. officinale was prepared by grinding the rhizome using a mortar and pestle. This was kept overnight in a rotatory shaker, after which it was filtered through a muslin cloth to yield an aqueous stock from which different concentrations were prepared for analysis. Similarly, a $5 \%(\mathrm{w} / \mathrm{v})$ aqueous leaf extract of $T$. foenum-graecum was prepared by homogenizing in distilled water using a mortar and pestle.

\section{Preparation of Enzyme Extract}

Maltase was extracted from S. cerevisiae using Baker's yeast granules (PRIME Instant Dry Yeast, India). The yeast was cultured in Yeast Extract Peptone Maltose growth medium containing maltose as an inducer for 18 hours in a rotatory shaker at $37^{\circ} \mathrm{C}$. The yeast culture was lysed by sonication using Branson ${ }^{\circledR}$ Sonifier 450 and centrifuged to obtain cell lysate, which was used as a source of crude maltase extract.

\section{Maltase Inhibition Assay}

The unit enzyme activity of maltase was defined as the amount of enzyme required to liberate one millimole of glucose per minute from the substrate maltose. The maltase enzyme activity was measured by Trinder's method ${ }^{21,22}$ using glucose oxidase (GOD) and peroxidase (POD). The reaction mixture was prepared by adding different volumes of aqueous plant extracts to $300 \mu \mathrm{L}$ of crude maltase and $700 \mu \mathrm{L}$ of $0.2 \mathrm{M}$ sodium phosphate buffer ( $\mathrm{pH}$ 6.8). To this reaction mixture, $500 \mu \mathrm{L}$ of $0.277 \mathrm{M}$ maltose solution was added as substrate and then incubated at $37^{\circ} \mathrm{C}$ for 15 minutes. The amount of glucose liberated from maltose hydrolysis in the reaction mixture was measured using the GOD-POD Diagnostic Kit. The absorbance was measured at $505 \mathrm{~nm}$ using a UV-Vis Spectrophotometer (SHIMADZU ${ }^{\circledR}$, Japan). The percentage maltase inhibitory activity was calculated as: [ $\{1$ - Enzyme Activity of Test/Enzyme Activity of Control) $\} \times 100$ ]; the control did not have the plant extract. Acarbose at various concentrations was included as a standard.

\section{Calculation of $I C_{50}$}

An inhibition curve for the aqueous plant extract was prepared by plotting the percentage maltase inhibitory activity against the concentration of extract. The concentration of the extract at which there is $50 \%$ maltase inhibitory activity under the assayed conditions is called the Inhibitory Concentration $_{50}\left(\mathrm{IC}_{50}\right)$.

\section{Statistical Analysis}

The measurement of maltase inhibitory activity for the different concentrations of aqueous plant extract was repeated in six independent assays and expressed as the mean \pm standard deviation. Statistical analysis was performed using an unpaired, two tailed $t$-test on Microsoft Excel Software. The criterion for statistical significance was at a $p$ value less than 0.05 .

\section{RESULTS}

The plant extracts showed a significant difference in the maltase enzyme activity from that of the control $(p<0.05)$. The efficacy of maltase inhibition of the plant extracts and acarbose was determined by calculating the $\mathrm{IC}_{50}$. Acarbose showed the highest potency of maltase inhibition with an $\mathrm{IC}_{50}$ value of $0.014 \%$ (Figure 1). The aqueous extract of $T$. foenum-graecum exhibited a higher potent maltase inhibitory activity with $\mathrm{IC}_{50}$ value of $1.05 \%$ (Figure 2) as compared to that of $Z$. officinale with $\mathrm{IC}_{50}$ value of $2.13 \%$ (Figure 3 ). The $\mathrm{IC}_{50}$ of both plants is graphically represented in comparison with that of Acarbose (Figure 4).

\section{DISCUSSION}

An important approach to diabetes treatment involves the regulation of blood glucose levels by delaying the release of glucose into the bloodstream using inhibitors for carbohydrate digesting enzymes such as maltase. In this study, the aqueous extracts of antidiabetic plants, Z. officinale and T. foenum-graecum, were screened for inhibitory activity towards the yeast maltase enzyme. Results indicated that both plants have significant maltase inhibitory activity $(p<0.05)$, and this could be attributed to the presence of phytochemicals in the plant extract. $Z$. officinale has active phytochemical constituents, which include phenols such as gingerol, terpenoids, and sesquiterpenoids like zingiberine, bisabolene, and zingibrol, and monoterpenoids such as camphene, cineole, geraniol, curcumene, and borneol. ${ }^{23}$ The hypoglycemic effects of $Z$. officinale may be attributed

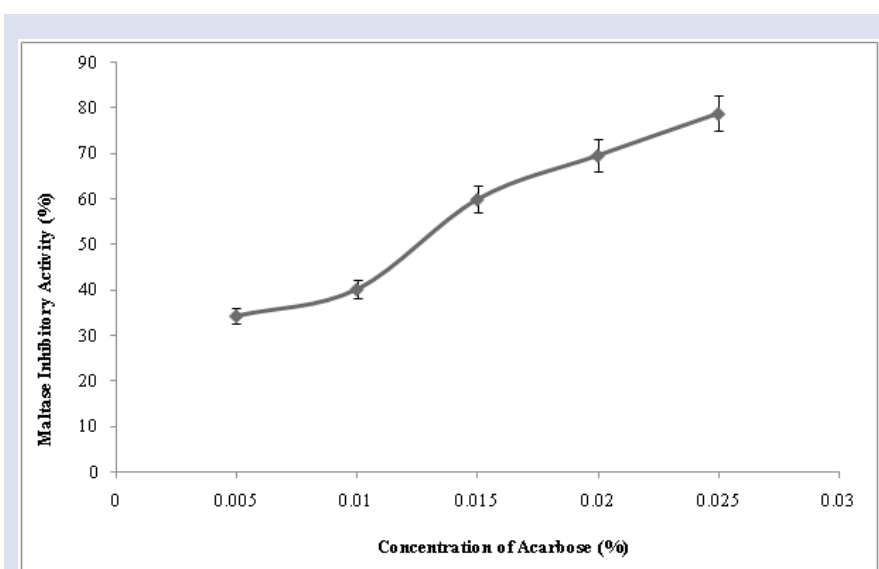

Figure 1: The maltase inhibitory activity (\%) of varying concentrations of Acarbose. The concentrations (\%) selected were 0.005, 0.01, 0.015, 0.02, and 0.025 . An enzyme blank and extract blank (control) was prepared for each concentration. The assay was performed five times and the data represent mean \pm standard deviation. Acarbose showed the highest potency of maltase inhibition with an $\mathrm{IC}_{50}$ value of $0.014 \%$ 


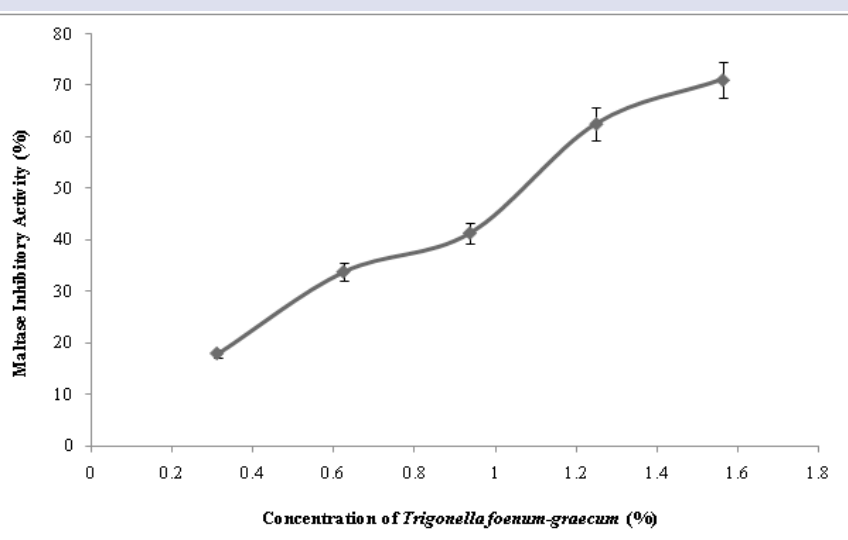

Figure 2: The maltase inhibitory activity (\%) of varying concentrations of aqueous leaf extract of Trigonella foenum-graecum. The concentrations (\%) selected were $0.3125,0.625,0.9375,1.25$, and 1.5625 . An enzyme blank and extract blank (control) was prepared for each concentration. The assay was performed six times and the data represent mean \pm standard deviation. The aqueous leaf extract of Trigonella foenum-graecum gave an $\mathrm{IC}_{50}$ value of $1.05 \%$

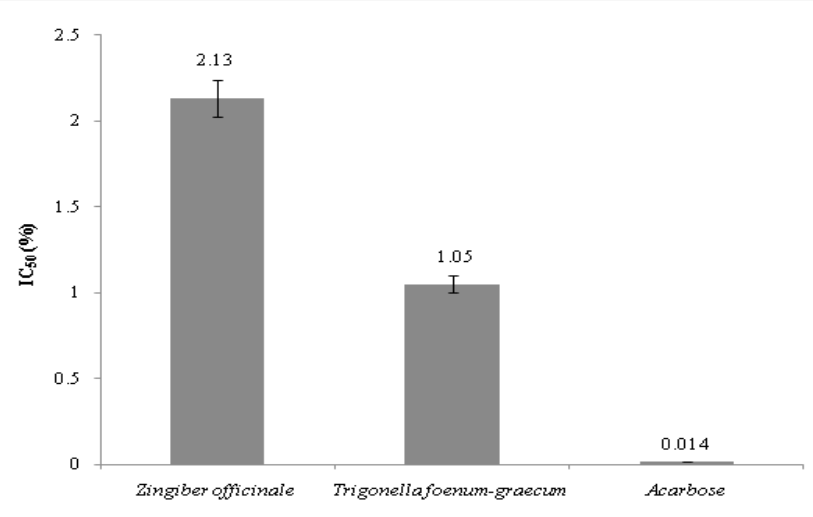

Figure 4: $I C_{50}$ values of aqueous plant extracts and Acarbose in maltase inhibition

to gingerol. Both in vivo studies using streptozotocin induced diabetic rats and in vitro studies have shown that gingerols are responsible for inhibition of alpha-glucosidases, increase in serum insulin levels, reducing blood sugar levels, ${ }^{24,25}$ and increasing the expression of glucose transporters such as GLUT-4, consequently increasing glucose uptake. ${ }^{26}$ T. foenum-graecum consists of phytochemicals such as saponins, 4-hydroxy isoleucine, and trigonelline. The seed and leaf extracts have shown antidiabetic properties in diabetic induced rats..$^{27,28}$ The hypoglycaemic effect of the leaf parts can be attributed to delay in gastric emptying by high fibre content, inhibition of carbohydrate digesting enzymes such as alpha-amylase and alpha-glucosidase. ${ }^{29}$ and stimulation of insulin secretion. ${ }^{30,31}$ Inhibition curves for $Z$. officinale and T. foenum-graecum revealed that there was an increase in the maltase inhibitory activity with increasing concentrations of the plant extract.

\section{CONCLUSION}

There are many Ayurvedic plants found in nature that have been reported with antidiabetic activity targeting different strategies. ${ }^{32}$ However, little research has been done to evaluate whether the antidiabetic activity of these plants are attributed to maltase inhibitory activity. In this study,

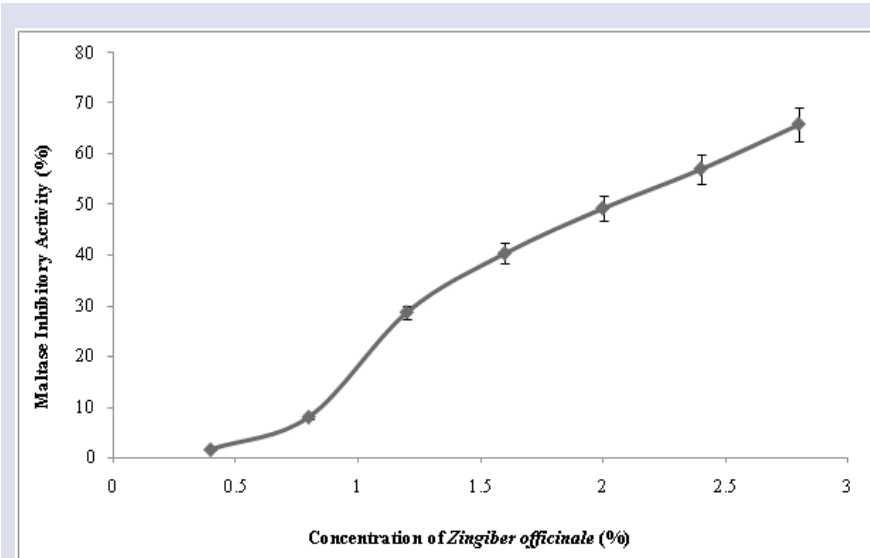

Figure 3: The maltase inhibitory activity (\%) of varying concentrations of aqueous extract of Zingiber officinale. The concentrations (\%) selected were $0.4,0.8,1.2,1.6,2.0,2.4$, and 2.8 . An enzyme blank and extract blank (control) was prepared for each concentration. The assay was performed six times and the data represent mean \pm standard deviation. The aqueous extract of Zingiber officinale gave $\mathrm{IC}_{50}$ value of $2.13 \%$

two antidiabetic plants, Z. officinale and T. foenum-graecum, were screened for maltase inhibitory activity. On the basis of statistical results, it can be concluded that both antidiabetic plants have significantly reduced the activity of maltase enzyme. Future prospects of this study would be screening a large number of plants to establish a correlation between potential antidiabetic activity and maltase inhibitory activity and to develop a maltase inhibitor "potency index" for plants using acarbose as the positive control and the $\mathrm{IC}_{50}$ values of the plants as a quantitative measure. If such a correlation can be established, an in vitro maltase inhibition assay could be used as a rapid tool to measure the potential of plants as antidiabetic tools, thus greatly reducing the use of animal models in future studies. This rapid tool has the potential of short-listing both known antidiabetic plants and other medicinal plants in terms of their maltase inhibitory activity. Further studies could include identification of the phytochemicals and determining their mode of inhibition by studying enzyme inhibition kinetics. The phytochemicals in antidiabetic plants have the potential to offer an alternative approach to developing functional foods and commercial antidiabetic agents for the treatment of diabetes.

\section{ACKNOWLEDGEMENT}

We would like to thank the director of the Central Instrumentation Facility (CIF), St. Xavier's College (Mumbai) for providing the laboratory apparatus that the study necessitated. We would also like to thank the director of the Blatter Herbarium, St. Xavier's College (Mumbai) for extending his services in the authorization of the plant material.

\section{CONFLICT OF INTEREST}

The authors declare no conflict of interest.

\section{ABBREVIATION USED}

GOD: glucose oxidase; POD: peroxidase; IC $_{50}$ : inhibitory concentration $_{50}$

\section{REFERENCES}

1. Whiting DR, Guariguata L, Weil C, Shaw J. IDF diabetes atlas: global estimates of the prevalence of diabetes for 2011 and 2030. Diabetes research and clinical practice. $2011 ; 94(3): 311-21$. 
2. Shaw JE, Sicree RA, Zimmet PZ. Global estimates of the prevalence of diabetes for 2010 and 2030. Diabetes Res Clin Pract 2010;87(1):4-14

3. Proks P, Reimann, Green N, Gribble F, Ashcroft F. Sulfonylurea Stimulation of Insulin Secretion. Diabetes 2002;51(3):S368-76

4. Viollet B, Guigas B, Sanz Garcia N, Leclerc J, Foretz M, Andreelli F. Cellular and molecular mechanisms of metformin: an overview. Clin Sci (Lond). 2012; 122(6):253-70

5. Deruiter JA. Overview of the antidiabetic agents. Endocrine Pharmacotherapy Module 2003;1-33

6. Greenfield JR and Chisholm DJ. Thiazolidinediones- mechanisms of action. Issues 2004: 1

7. Bischoff $\mathrm{H}$. The mechanism of alpha-glucosidase inhibition in the management of diabetes. Clin Invest Med. Medecine clinique et experimentale 1995: 18(4):303-11

8. Yamagishi S, Nakamura K, Takeuchi M. Inhibition of postprandial hyperglycemia by acarbose is a promising therapeutic strategy for the treatment of patients with the metabolic syndrome. Med Hypotheses 2005; 65(1):152-4

9. Bell DS. Importance of postprandial glucose control. South Med J 2001;94(8):804

10. Casirola DM and Ferraris RP. $\alpha$-Glucosidase inhibitors prevent diet-induced increases in intestinal sugar transport in diabetic mice. Metabolism 2006; 55(6):832-41

11. Reuser AJ and Wisselaar HA. An evaluation of the potential side-effects of $\alpha$-glucosidase inhibitors used for the management of diabetes mellitus. Eur $J$ Clin Invest 1994;24(S3):19-24

12. Campbell LK, Baker DE, Campbell RK. Miglitol: assessment of its role in the treatment of patients with diabetes mellitus. Ann Pharmacother 2000;34(11):1291-301

13. Scott LJ and Spencer CM. Miglitol. Drugs 2000;59(3):521-49

14. Kast RE. Acarbose related diarrhea: increased butyrate upregulates prostaglandin E. Inflamm Res 2002;51(3):117-8

15. Rosak $\mathrm{C}$ and Mertes $\mathrm{G}$. Critical evaluation of the role of acarbose in the treatment of diabetes: patient considerations. Diabetes, metabolic syndrome and obesity: targets and therapy 2012;5:357

16. Dabhi AJ, Bhatt NR, Shah MJ. Voglibose: an alpha glucosidase inhibitor. J Clin Diagn Res 2013;7(12):3023

17. Kalra S. Alpha glucosidase inhibitors. JPMA. J Pak Med Assoc 2014;64(4):474-6

18. Marles RJ and Farnsworth NR. Antidiabetic plants and their active constituents. Phytomedicine 1995;2(2):137-89
19. Patel DK, Prasad SK, Kumar R, Hemalatha S. An overview on antidiabetic medicinal plants having insulin mimetic property. Asian Pac J Trop Biomed 2012:2(4):320-30

20. Coman C, Rugina OD, Socaciu C. Plants and natural compounds with antidiabetic action. Not Bot Horti Agrobo Cluj-Napoca 2012;40(1):314

21. Trinder P. Determination of glucose in blood using glucose oxidase with an alternative oxygen acceptor. Ann Clin Biochem 1969;6(1):24-7

22. Barham $D$ and Trinder P. An improved colour reagent for the determination of blood glucose by the oxidase system. Analyst 1972;97(1151):142-5

23. Salim KS. Hypoglycemic Property of Ginger and Green Tea and Their Possible Mechanisms in Diabetes Mellitus. Open Conf Proc J 2014;5:13-9

24. Al-Amin ZM, Thomson M, Al-Qattan KK, Peltonen-Shalaby R, Ali M. Anti-diabetic and hypolipidaemic properties of ginger (Zingiber officinale) in streptozotocininduced diabetic rats. Br J Nutr 2006:96(4):660-6

25. Rani M, Padmakumari KP, Sankarikutty B, Lijocherian O, Nisha VM, Raghu KG. Inhibitory potential of ginger extracts against enzymes linked to type 2 diabetes, inflammation and induced oxidative stress. Int J Food Sci Nutr 2011;62(2):106-10

26. LiY, Tran VH, Duke CC, Roufogalis BD. Gingerols of Zingiber officinale enhance glucose uptake by increasing cell surface GLUT4 in cultured L6 myotubes. Planta Med 2012;78(14):1549-55

27. Mowla A, Alauddin M, Rahman MA, Ahmed K. Antihyperglycemic effect of Trigonella foenum-graecum (Fenugreek) seed extract in alloxan-induced diabetic rats and its use in diabetes mellitus: a brief qualitative phytochemical and acute toxicity test on the extract. Afr J Trad 2009;6(3):255-61

28. El-Dakak AM, El-Rahman HS, El-Nahal DM. Comparison studies between aqueous Lepidium sativum L., Lupinus albus and Trigonella foenum-graecum seeds, and their mixture extracts on streptozotocin-induced diabetic rats. J Appl Sci Res 2013:9(4):2965-82

29. Ganeshpurkar A, Diwedi V, Bhardwaj Y. In vitro $\alpha$-amylase and $\alpha$-glucosidase inhibitory potential of Trigonella foenum-graecum leaves extract. Ayu 2013; 34(1):109

30. Chauhan A, Sharma PK, Srivastava P, Kumar N, Dudhe R. Plants having potential antidiabetic activity: a review. Der Pharmacia Lettre 2010;2(3):369-87

31. Dwivedi $\mathrm{C}$ and Daspaul S. Antidiabetic herbal drugs and polyherbal formulation used for diabetes: a review. J Phytopharmacol 2013;2(3):44-51

32. Bnouham M, Ziyyat A, Mekhfi H, Tahri A, and Legssyer A. Medicinal plants with potential antidiabetic activity - A review of ten years of herbal medicine research (1990-2000). Int J Diabetes \& Metabolism 2006;14(1):1

\section{GRAPHICAL ABSTRACT}

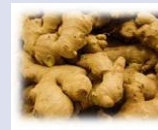

Zingiber officinale (Aqueous Extract)

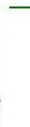
$\rightarrow$ Detection of Maltase Inhibitory Activity . Invitro Enzyme Inhibition Assay - In vitro Enzyme Inhibition Assay Using crude maltase enzyme from
Saccharomyces cerevisiae Saccharomyces cerevisiae
Calculate $\mathrm{IC}_{50}$ of both plant extracts
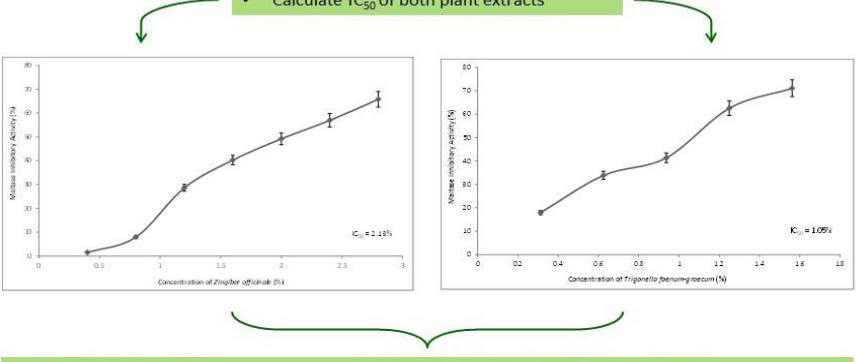

Z. officinale and $T$. foenum-graecum $\rightarrow$ significant maltase inhibitory activity

Antidiabetic property of the two plants may be attributed to their maltase inhibitory activity

\section{SUMMARY}

- The aqueous extract of $T$. foenum-graecum exhibited potent maltase inhibitory activity with $I C_{50}$ value of $1.05 \%$

- The aqueous extract of $Z$. officinale exhibited potent maltase inhibitory activity with $I C_{50}$ value of $2.13 \%$.

- The synthetic drug Acarbose showed the highest potency of maltase inhibition with an $\mathrm{IC}_{50}$ value of $0.014 \%$.

- Z. officinale and T. foenum-graecum have significant maltase inhibitory activity $(p<0.05)$ and the antidiabetic property of the two plants may be attributed to their maltase inhibitory activity.

\section{ABOUT AUTHORS}

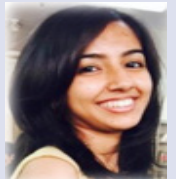

Janhavi Damani: Obtained her Master's degree in Life Science from St. Xavier's College, Mumbai, India. She has also completed her Bachelors in Life Science from Jai Hind College, Mumbai, India. She has previously undertaken two undergraduate research projects in the field of biochemistry and microbiology.

Cite this article: Damani JJ, Gupta RP, Mangalore N. Maltase Inhibitory Activity of Aqueous Extracts of Zingiber officinale Rosc. and Trigonella foenum-graecum Linn.. Pharmacog J. 2018;10(2):226-9. 